This document is published in:

Setchi, R; et al. (eds.) (2010) Knowledge-Based and Intelligent Information and Engineering Systems: 14th International Conference, KES 2010, Cardiff, UK, September 8-10, 2010, Proceedings, Part IV. (Lecture Notes in Computer Science, 6279). Springer, pp. 357- 364.

DOI: http://dx.doi.org/10.1007/978-3-642-15384-6_38

(C) 2010 Springer-Verlag Berlin Heidelberg 


\title{
Adaptation of an Evaluation System for e-Health Environments
}

\author{
Nayat Sánchez-Pi and José Manuel Molina \\ Carlos III University of Madrid, \\ Avda de la Universidad Carlos III, 22. 28270, \\ Madrid, Spain \\ nayat.sanchez@uc3m.es, josemanuel.molina@uc3m.es
}

\begin{abstract}
The increase in ageing of European population implies a high cost in economy and society in any European country and it can be reduced if we pay attention and develop home care systems. Evaluation of these systems is a critical and challenging issue but seldom tackled. It is important before evaluating a system to figure out what is the evaluation goal. In our case, such a goal is to evaluate enhanced user experience and beyond the evaluation goal it is also a central concern about what to evaluate. In this paper we propose a multi-agent home care system where we describe how agents coordinate their decisions to provide e-services to patients when at home after hospitalization. Finally we center our proposal on the adaptation of an evaluation system, previously developed, to support the challenges of an e-Health environment and also the multi-user evaluation. These evaluation methods (online/offline) will provide user's (patients, patient's relatives and healthcare professionals) feedback into the system.
\end{abstract}

\section{Introduction}

The feasibility of using information and communications technologies (ICT), such as sensor networks, radio frequency identification (RFID) and Universal Mobile Telecommunications System (UMTS), has led to improve e-services and applications in the ambience of electronic healthcare (e-Health) [1]. The European Furthermore, the increase in ageing of European population and the treatment of chronic and disabled patients implies a high cost in terms of time and effort. Sometimes patients and also healthcare workers consider treatments in health centres unnecessary as they could collapse national health services and increase costs. On the other hand, we face the problem of the patients living in rural areas, where is difficult to access. To face these challenges we need to differentiate medical assistance in health centres from. assistance in a ubiquitous way that it is possible due to the advances in communication technologies. Ubiquitous healthcare (u-health) is an emerging area of technology that uses a large number of environmental and patient sensors to monitor and improve patients' physical and mental condition. U-Health focuses on e-Health applications that can provide health care to people anywhere at any time using information and 
communication technologies. Besides, innovative approaches in mobile healthcare (m-Health) have also been developed as a footbridge between e-Health and u-Health. Several initiatives, such as Mobihealth [2], XMotion [3] and MyHearth [4] have investigated the feasibility and benefits of mobile healthcare services and applications. There have been also several attempts to developed home care systems, such as Gator Tech House [5], PAUL (Personal Assistant Unit for Living) [6] and AMADE [7]. However, these initiatives do not provide a clear application framework that simplifies the development of e-health applications and at the same time do not provide an evaluation system taking into account the contextual information as well as the user's opinion.

The main contributions of this work are the following:

- i) Effectively adapting the design and architecture of an agent-based developed in previous works [8] [9] to an agent-based home care system in order to provide m-services to patients / caregivers / patient's relatives when at home after patients hospitalization.

- ii) Adapting the evaluation system developed in previous work [10] to support the challenges of u-health environment, and also the challenge of providing multi-user evaluation and feedback into the system.

The remainder of this paper is structured as follows: Section 2 presents a scenario of u-commerce environment and its evaluation from the users' point of view developed in previous work. Section 3 describes the MAS adaptation to e-health environment. Section 4 presents a scenario of e-health, and the evaluation system adaptation to e-health environment. Section 5 presents some conclusions and directions for future work.

\section{User Evaluation for Context-Aware System Based in MAS}

There are several methods [11] and approaches used to evaluate context-aware systems. Evaluation of these systems is a critical and challenging issue but seldom tackled. As there are no established evaluation frameworks in literature, in previous work [10] we have used, first of all, a pre-implementation evaluation method as the 'Wizard of Oz' [12]. And latter we used a method called 'revisiting the hypotheses' [11], which he divides it into four hypotheses to be investigated. Regarding to the evaluation from the users point of view, in [9] we based on two propositions an offline customers evaluation (once the user has finished using the system and that can be accessible via: www.giaa.inf.uc3m.es/u-shopping/myfeedback/) and an online customers evaluation in a u-commerce environment. In any of them, customer makes a quantitative evaluation by defining a utility function and mapping the satisfaction state to numeric value. The value of quality of shopping/vendor services corresponds to the users feedback and can have values like: (1) Correct, (2) Different order or (3) Incorrect for every attribute.

The evaluation for a multi-agent context-aware system for a u-commerce environment is represented by the following scenario where a young customer 'John' 


Scenario u-Commerce:
User name: John Mayer
Location: Parque Sur Shopping Center
Date and Time: $2009-12-14,17: 00$
Device: PDAQ 00-18-41-32-0B-59
Objective: To buy some new clothes, find new offers
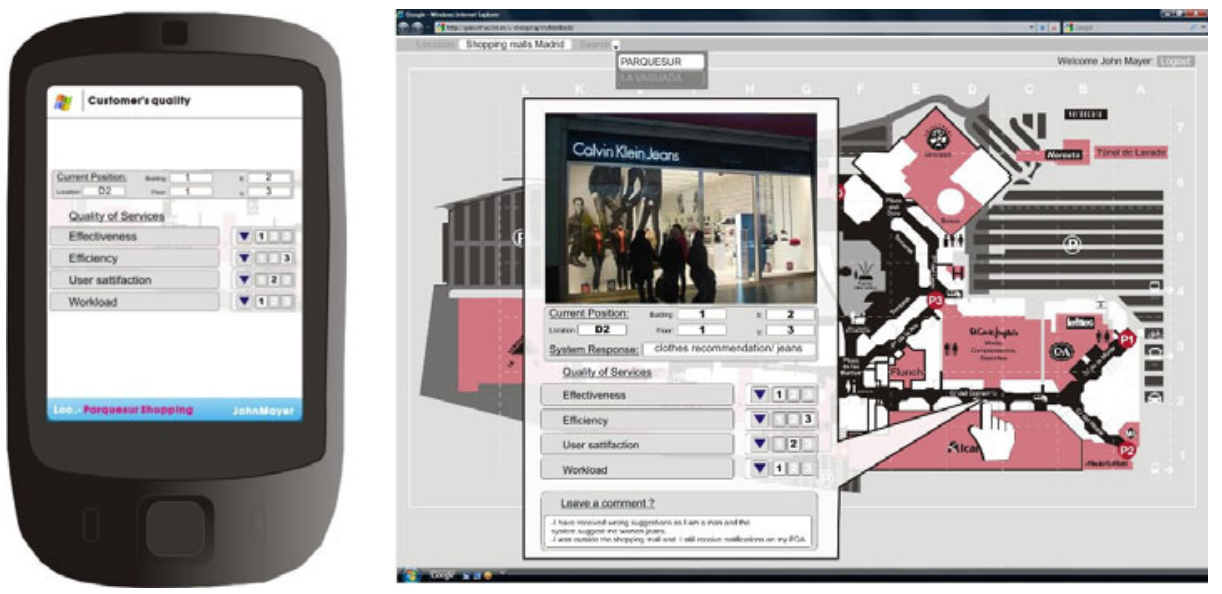

Fig. 1. Online (left) and Offline (right) quality evaluation

goes to 'Parque Sur' shopping mall because he needs to buy some new clothes. See Fig 1.

\section{MAS Adaptation to e-Health Environment}

Tourism, Healthcare, Education, Transportation, etc., are some of the environments where been developed ubiquitous systems and applications above AmI vision. In the case of modern healthcare, it includes user mobility allowing people at risk or patients with proved health problems to continue their usual life at their homes and work places. Furthermore, health care professionals also need to access and input medical or patient information from anywhere, at any time in their daily ward rounds [13] [14] [15]. Hence, mobile healthcare systems can facilitate efficient and effective patient care information input and access at the point of patient care.

Taking into account all of the above, we have adapted the design and architecture of a multi-agent system developed in previous works to support u-health services provisioning [8] [10]. The redesign includes new features to support uhealth services and applications where users will become 'patients or caregivers or patient's relatives' and where a new categories of agent appear: 'evaluation 


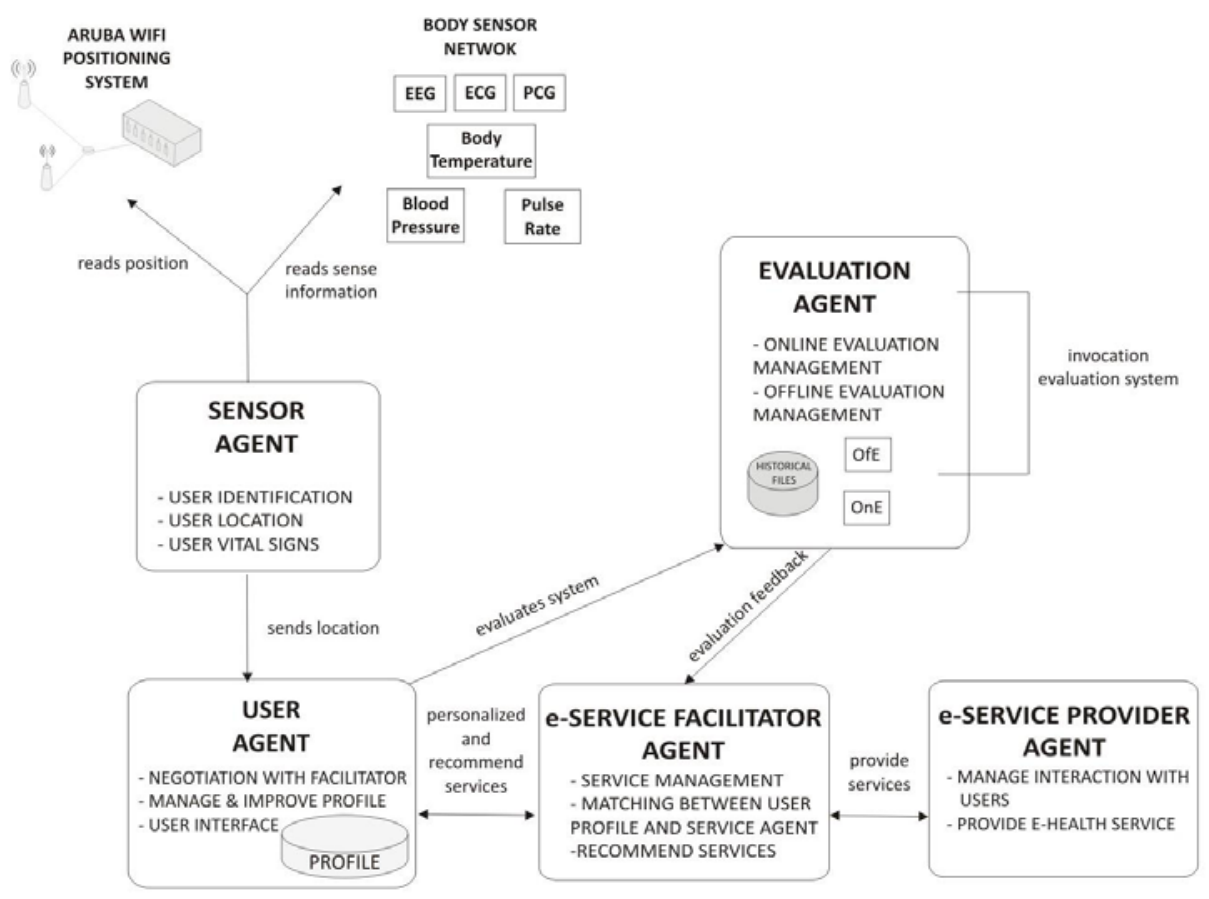

Fig. 2. MAS architecture adaptation

agent'. See fig 2. The interaction between the different agents is described by the following sequence of phases:

- i) The Aruba Positioning system the patient's position while at WiFi home network and the Body Sensor Network provides the information regarding each sensor parameter;

- i) The sensor agent provides sensor information to the user agent;

- iii) Once the user agent knows its location, and its vital signs, sends it to the e-service facilitator agent. It also provides information regarding the type of user is using the system (patient/caregivers/patient's relatives);

- iv) The e-service facilitator agent sends the e-service provider agent the identification of the user agent that provides the kind of e-services required by the user agent;

- v) The user agent asks a specific e-service provider agent to provide it with the required e-service;

- vi) E-service provider agent asks the user agent about context information to be used during the interaction to provide the personalized e-service;

- vii) User agent provides the required context information to the e-service provider agent;

- viii) Interaction between the user agent and the e-service provider agent using the adaptation provided by the previous step; 
- ix) Once the interaction and the provisioning of e-service tool place, evaluation agent ask the e-service facilitator agent about the type of user;

$-\mathrm{x}$ ) Evaluation agent invokes Online/Offline evaluation system depending of the type of user; xi) Historical files are stored for analysis and feedback is provided into the system.

\section{User Evaluation for e-Health System Based in MAS}

Adaptation of the evaluation system developed in previous work [10], to suit e-health environments takes into account not only the characteristics of the environment, but also the quantitative user evaluation. Quality process has two distinct facets: technical quality and functional quality. Technical quality refers to the accuracy of medical diagnoses and procedures, and is generally comprehensible to the professional community, but not to patients [16]. Patients essentially perceive functional quality as the manner in which the service is delivered; while healthcare professional can be capable of making a technical quality evaluation.

There are several proposals regarding service quality measurement. Some of them are: SERVQUAL instrument proposed by Parasuraman [17]; SERVPERF [18] [19]; Yoo and Donthu [20] and Zhang and Prybutok [21]. Regarding this, for ehealth environment we consider two groups of users: patients/caregivers/patient's relatives and health professionals. The first group will be able to make an online evaluation $(\mathrm{OnE})$ of the system, for which we have defined some service quality measurement, and the second one, an offline evaluation (OffE) with other service quality measurement that evaluates, in this case, the technical quality of the system response.

Main contributions regarding adaptation of user evaluation are:

- i) First, as the awareness of the system has been adapted for the e-health environment, the evaluation will be done based not only on the patients' location (as we did in [10], but also on his vital signs: blood pressure (BP); pulse rate $(\mathrm{PR})$; respiration rate $(\mathrm{RR})$ and body temperature $(\mathrm{BT})$. We based on the fact that the system is composed of a set of different sensors connected to a PDA that transmits, in a secure way, all the patient data (location and vital signs) to a central server in the hospital. The authorized doctors can access this medical information from their computers (inside the hospital or even outside) afterwards.

- ii) In the case of OnE, main contributions related to the adaptation of the service quality measurement to e-health are: Quality parameters measures the service quality gap between client expectations and perceptions of 5 quality attributes (on a five-point scale: strongly disagree $=1$ to strongly agree $=5$ ). Attributes are: easy of use; proceeding speed and effectiveness; reliability.

- iii) For OffE, we explore the e-service quality dimensions based on a review of the development of e-service quality scales and the SERVQUAL scale [17]. It proposes an 8-dimension scale but we will adapt this scale and 
Scenario e-Health: Elderly in a wheelchair + e-health services

Event part: When the wheelchair (it is supposed to be the elderly person) with RFID-tag is detected in the TV room.

Condition part: (and) vital signs are: $\mathrm{BP}: 130 / 85$; PR: 80 ; $\mathrm{RR}=17$; $\mathrm{BT}: 37^{\circ} \mathrm{C}$. Action part: (then) activate the EMERGENCY MEDICATION ALERT SERVICE and VoIP functionality on the PDA and through a voice message indicates l"Mr. Mark you should take the medication for high pressure. Please take 1 pill right now".

add 2 more dimensions: system design (Appealing and well organized website; Consistent and standardized navigation; Well-organized appearance of user interface; Quickly downloading), reliability (Accurate delivery e-service; Complete order e-service; System being truthful about its diagnosis; The online e-service always correct; Keeping e-service promise; Accurate online e-service records; Website always available), fulfilment (Information on eservices available when need it; System runs smoothly in the transaction process; Accurate promises about delivery e-service when scheduled; Available to modify and/or defer the e-service process at any time without commitment), security (Protect the personal data of customers; Good reputation), responsiveness (Adequate contact information and performance; Prompt responses to customers; Timely responses to customers; Adequate response

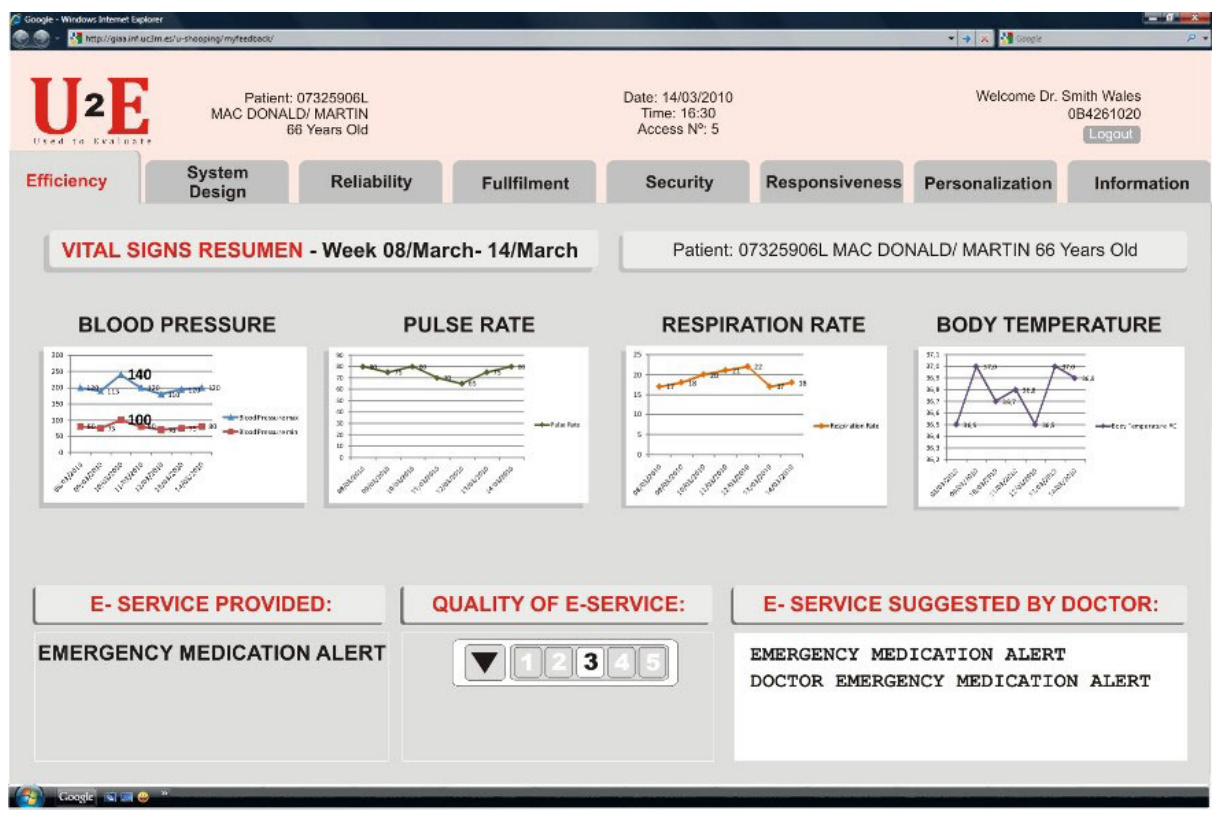

Fig. 3. Online (left) and Offline (right) quality evaluation 
time), personalization, information and efficiency. Likerts's five point scale is used (strongly disagree $=1$ to strongly agree $=5$ ).

The evaluation for a multi-agent e-health system is represented by the following scenario where an elder patient stays home after hospitalization for a treatment. So, once the e-service is provided to the patient, the OnE evaluation system is invoked by the evaluation agent and patient/caregiver/patient relatives can make the evaluation of the e-services received filling the evaluation form. Doctor or health professional in charge of following the patients' file, can also evaluate the system behaviour as see in Fig 3. In this case Dr. makes an offline evaluation of the behaviour of the system during a week. Dr. suggests the system, in a similar case, to activate the DOCTOR EMERGENCY MEDICATION'S ALERT that will send a message to the doctor, so he can be notified immediately. So our system could then: i) discriminate between contextual information; ii) allow authorized health professional to suggest the correct e-services that should be provided in each case; iii) allow patients/caregiver/patients' relatives give their opinion about the received e-service in each case. In order to give a general measure of the e-service facilitator agent results over the satisfactory cases, we evaluate how close the e-service facilitator agent's ranking is to the user's own ranking as presented in [10].

\section{Conclusions and Future Research Agenda}

Evaluation of e-health systems from the users' point of view is a critical and challenging issue but seldom tackled. It is important before evaluating a system to figure out what is the evaluation goal and who will evaluate the system. We adapted an evaluation system, previously developed, to support the challenges of e-Health environment, and also the multi-user evaluation. Patients, patient's relatives and caregivers are part of the same group of user evaluators that uses the online user evaluation system through the PDA to evaluate the system output. On the contrary, authorized healthcare professionals can provide feedback into the system taking into account the vital signs of the patient, and the e-service provided by the system. In order to give a general measure of the e-service facilitator agent's results over the satisfactory cases, we evaluate how close the e-service facilitator agent's ranking is to the user's own ranking. For this, we chose the Manhattan distance between the position of the first three products selected by the user and their position in the system ranking [10]. As future trends, we plan to give the statistical results of this analysis and provide the feedback to the system.

\section{Acknowledgements}

This work was supported in part by Projects CICYT TIN2008-06742-C02-02/ TSI, CICYT TEC2008-06732-C02-02/TEC, CAM CONTEXTS (S2009/ TIC-1485) and DPS2008-07029-C02-02. 


\section{References}

1. Wyatt, J., Sullivan, F.: Ehealth and the future: promise or peril? British Medical Journal 331, 1391 (2005)

2. Van Halteren, A., Bults, R., Wac, K., Konstantas, D., Widya, I., Dokovsky, N., Koprinkov, G., Jones, V., Herzog, R.: Mobile patient monitoring: The mobihealth system. The Journal on Information Technology in Healthcare 2(5), 365-373 (2004)

3. X-motion project webpage (2004)

4. Myheart project webpage

5. Helal, S., Mann, W., El-Zabadani, H., King, J., Kaddoura, Y., Jansen, E.: The gator tech smart house: A programmable pervasive space. Computer, 50-60 (2005)

6. Floeck, M., Litz, L.: Integration of home automation technology into an assisted living concept. In: Assisted Living Systems-Models, Architectures and Engineering Approaches (2007)

7. Fraile, J., Bajo, J., Corchado, J.: Am ade: Developing a multi-agent architecture for home care environments (2008)

8. Sánchez-Pi, N., Carbó, J., Molina, J.: Jade/leap agents in an aml domain. In: Corchado, E., Abraham, A., Pedrycz, W. (eds.) HAIS 2008. LNCS (LNAI), vol. 5271, pp. 62-69. Springer, Heidelberg (2008)

9. Sánchez-Pi, N., Molina, J.: A multi-agent platform for the provisioning of ucommerce services. In: 28th North American Fuzzy Information Processing Society Annual Conference (2009)

10. Sánchez-Pi, N., Molina, J.: A multi-agent approach for the provisioning of e-services in u-commerce environment. Internet Research 20 (2010), ISSN: 1066-2243

11. Schmidt, A.: Ubiquitous Computing- Computing in Context. PhD thesis (November 2002)

12. Dahlback, N., Jonsson, A., Ahrenberg, L.: Wizard of oz studies-why and how. Knowledge-Based Systems 6(4), 258-266 (1993)

13. Haux, R.: Health information systems-past, present, future. International Journal of Medical Informatics 75(3-4), 268-281 (2006)

14. Johnson, C., Turley, J.: The significance of cognitive modeling in building healthcare interfaces. International Journal of Medical Informatics 75(2), 163-172 (2006)

15. Reuss, E., Menozzi, M., Buchi, M., Koller, J., Krueger, H.: Information access at the point of care: what can we learn for designing a mobile cpr system? International Journal of Medical Informatics 73(4), 363-369 (2004)

16. Bopp, K.: How patients evaluate the quality of ambulatory medical encounters: a marketing perspective. Journal of Health Care Marketing 10(1), 6-15 (1990)

17. Parasuraman, A., Zeithaml, V., Berry, L.: Servqual: a multiple-item scale for measuring consumer perceptions of service quality. Retailing: Critical Concepts 64(1), $140(2002)$

18. Gronroos, C.: Service management and marketing: managing the moments of truth in service competition. Jossey-Bass, San Francisco (1990)

19. Cronin Jr., J., Taylor, S.: Measuring service quality: a reexamination and extension. The Journal of Marketing 56(3), 55-68 (1992)

20. Yoo, B., Donthu, N.: Developing a scale to measure the perceived quality of an internet shopping site (sitequal). Quarterly Journal of Electronic Commerce 2, 31-46 (2001)

21. Zhang, X., Prybutok, V.: A consumer perspective of e-service quality. IEEE Transactions on Engineering Management 52(4), 461-477 (2005) 